RESEARCH REPORT

\title{
Socioeconomic differences in attitudes and beliefs about healthy lifestyles
}

\section{J Wardle, A Steptoe}

J Epidemiol Community Health 2003;57:440-443

See end of article for authors' affiliations

.....................

Correspondence to: Professor Jane Wardle, Cancer Research UK,

Health Behaviour Unit, Department of

Epidemiology and Public

Health, University College

London, 2-16 Torrington

Place, London WC1E 6BT,

UK; j.wardle@ucl.ac.uk

Accepted for publication 10 October 2002
Study objectives: The factors underlying socioeconomic status differences in smoking, leisure time physical activity, and dietary choice are poorly understood. This study investigated attitudes and beliefs that might underlie behavioural choices, including health locus of control, future salience, subjective life expectancy, and health consciousness, in a nationally representative sample.

Design: Data were collected as part of the monthly Omnibus survey of the Office of National Statistics in Britain.

Participants: A stratified, probability sample of 2728 households was selected by random sampling of addresses. One adult from each household was interviewed.

Main results: Higher SES respondents were less likely to smoke and more likely to exercise and eat fruit and vegetables daily. Lower SES was associated with less health consciousness (thinking about things to do to keep healthy), stronger beliefs in the influence of chance on health, less thinking about the future, and lower life expectancies. These attitudinal factors were in turn associated with unhealthy behavioural choices, independently of age, sex, and self rated health.

Conclusions: Socioeconomic differences in healthy lifestyles are associated with differences in attitudes to health that may themselves arise through variations in life opportunities and exposure to material hardship and ill health over the life course.
S ocioeconomic differences in health behaviours such as moking, leisure time physical activity, and dietary choice have been consistently described in population surveys $^{1-3}$ and there is evidence that the gradient in some behaviours, for example smoking and weight control, is increasing. ${ }^{45}$ The determinants of socioeconomic differences in health behaviours are poorly understood but are likely to include characteristics of the physical environment (for example, places to walk, availability of healthy foods), social norms (for example, smoking levels in the community, eating habits), and the costs of health protective behaviours. Individual knowledge, attitudinal, and motivational factors stemming from educational access, life experiences, and the general level of health consciousness expressed within the local social environment, are also relevant. ${ }^{67}$ In this study, we investigated attitudes that might underlie the gradient in behavioural choices, focusing on three aspects. The first is perceived control over health, as healthy behaviours have been shown to be associated with stronger beliefs in personal or internal control, and weaker beliefs in chance or external factors. ${ }^{8}$ We hypothesised that social class would be inversely related to the strength of beliefs in chance and positively related to beliefs in internal control. Secondly, orientation towards the future and expectations about longevity were assessed. Healthy lifestyles are only likely to benefit health over the longer term, so socioeconomic differences in thinking about the future and expectations about the life span might affect motivation to maintain healthy lifestyles. Thirdly, we measured awareness of the importance of lifestyle, hypothesising that affluent respondents would think more often about things they could do to stay healthy than would less privileged groups.

These factors were assessed in a national representative sample of adults in Britain. As the study was cross sectional, it is possible that some variations in attitude might result from pre-existing health differences; for example, poor health might lead to fatalistic views about longevity. Self ratings of health have repeatedly been shown to predict mortality, and are also inversely associated with socioeconomic position. Self rated health was therefore recorded and included as a cofactor in analyses of attitudes.

\section{METHODS}

Data were collected using questions added to the monthly omnibus survey carried out by the Office of National Statistics. This is a multipurpose survey devised for the use of non-profit making organisations, and the items analysed here were included in the September 2000 survey. A probability sample of 100 postal sectors stratified by region of the country, housing type, and socioeconomic grouping of head of household was randomly selected, and private addresses were randomly selected from each sector. Each household was visited by a trained interviewer, and one randomly selected member of the household aged 16 years or over was assessed. ${ }^{9}$ From a target sample of 2728 eligible addresses, 748 respondents refused to be interviewed, and 278 could not be contacted after three attempts, so 1691 (62\%) interviews were achieved (footnote*).

\section{Measures}

Socioeconomic status was indexed by occupational social class, based on the registrar general's classification of current or last occupation. People who have never worked or provided inadequate descriptions $(n=136)$ were excluded from analyses.

\footnotetext{
* In comparison with the general population in mid-2000, a slightly lower proportion of young adults aged $16-24$ responded $111.2 \% \mathrm{~V}$ $13.7 \%)$, while the proportion of respondents aged $55-64$ years $(16.0 \%)$ was greater than population estimates (13.2\%). However, the omnibus survey samples only people living in private households, whereas population estimates also include students living away from home in college accommodation, and staff living in National Health Service accommodation.
} 
Table 1 Health behaviour and self rated health

\begin{tabular}{|c|c|c|c|c|c|}
\hline & \multirow[b]{2}{*}{ Social class } & \multicolumn{2}{|c|}{ Percentages } & \multirow{2}{*}{$\begin{array}{l}\text { Odds ratio for social } \\
\text { class, adjusted for age } \\
\text { and sex }(95 \% \mathrm{Cl})\end{array}$} & \multirow{2}{*}{$\begin{array}{l}\text { Odd ratio for social class, } \\
\text { adjusted for age, sex, and } \\
\text { self rated health ( } 95 \% \mathrm{CI})\end{array}$} \\
\hline & & $\begin{array}{l}\text { Men } \\
(n=758)\end{array}$ & $\begin{array}{l}\text { Women } \\
(n=933)\end{array}$ & & \\
\hline \multicolumn{6}{|l|}{ Age distribution } \\
\hline$<35$ years & & 24.5 & 24.5 & & \\
\hline $35-49$ years & & 26.0 & 26.9 & & \\
\hline $50-64$ years & & 26.5 & 22.1 & & \\
\hline$\geqslant 65$ years & & 23.0 & 26.5 & & \\
\hline \multirow[t]{3}{*}{ Current cigarette smoking } & Class I/II & 19.6 & 22.1 & 1 & 1 \\
\hline & Class III & 28.5 & 26.3 & $1.50(1.15$ to 1.96$)$ & $1.39(1.06$ to 1.82$)$ \\
\hline & Class IV/V & 42.0 & 36.2 & 2.65 (1.94 to 3.62$)$ & 2.36 (1.72 to 3.24$)$ \\
\hline \multirow{3}{*}{$\begin{array}{l}\text { No vigorous leisure time physical activity over } \\
\text { the past week }\end{array}$} & Class I/II & 49.7 & 57.8 & 1 & 1 \\
\hline & Class III & 61.2 & 71.1 & 1.65 (1.31 to 2.09$)$ & $1.46(1.15$ to 1.86$)$ \\
\hline & Class IV/V & 61.6 & 80.2 & 2.17 (1.60 to 2.94$)$ & 1.81 (1.32 to 2.47$)$ \\
\hline \multirow[t]{3}{*}{ Fewer than one portion of fruit per day } & Class I/II & 36.4 & 19.8 & 1 & 1 \\
\hline & Class III & 47.4 & 31.5 & $1.74(1.36$ to 2.24$)$ & $1.67(1.31$ to 2.14$)$ \\
\hline & Class IV/V & 49.1 & 37.7 & 2.21 (1.64 to 2.98$)$ & 2.08 (1.54 to 2.82$)$ \\
\hline \multirow[t]{3}{*}{ Fewer than one portion of vegetables per day } & Class I/II & 24.1 & 13.3 & 1 & 1 \\
\hline & Class III & 37.1 & 26.6 & 2.12 (1.62 to 2.77$)$ & 1.95 (1.49 to 2.57$)$ \\
\hline & Class IV/V & 44.6 & 31.4 & 2.89 (2.10 to 3.99$)$ & 2.57 (1.86 to 3.57$)$ \\
\hline \multirow[t]{3}{*}{ Fair or poor self rated health } & Class I/II & 17.7 & 15.6 & 1 & \\
\hline & Class III & 31.3 & 26.8 & $2.00(1.51$ to 2.65$)$ & \\
\hline & Class IV/V & 34.8 & 38.2 & $2.85(2.05$ to 3.94$)$ & \\
\hline
\end{tabular}

Health behaviours: participants were asked whether they currently smoked, and whether they had carried out any vigorous leisure time physical activity over the past week. They were also asked how often they ate a serving of fruit and vegetables.

Health locus of control: internal locus of control was assessed with three items from the internal scale of the Multidimensional Health Locus of Control scale, ${ }^{10}$ (for example, "My physical wellbeing depends on how well I take care of myself"), while chance locus of control was assessed with the three items from the chance scale (for example, "Good health is largely a matter of good luck"). Average scores could range from 1 (low) to 5 (high).

Future salience was assessed with the questions "How often do you think about what will be happening in your life: in one months time? in three months time? in six months time? in one years time? in two years time? in five years time? in ten years time?". Participants answered each question with one of the following responses: rarely, not very often, fairly often, or very often.

Expectations of longevity were assessed with the question "Many people feel that they have some idea about their life span. Thinking about your life, what age do you think you will live to?" The following choices were given up to 70,70 to 79,80 to 89,90 to 99 , and over 100 .

Health consciousness: conscious awareness of the influence of lifestyle on health was assessed with the question "How often do you think about things that you might do to keep yourself healthy or improve your health?" The response options were several times a day, at least once a day, every two or three days, about once a week, about once a month, every few months, less than once a year, rarely or never. Participants were also asked how often they thought about illnesses that they might get in the future, with the same response options.

Self rated health was assessed with the question "In general, would you say that your health is excellent/very good/good/ fair/poor".

\section{Statistical analysis}

Respondents were categorised into three social class groups for analysis based on the registrar general's scheme: classes I and II, III non-manual and manual, and IV and V. Frequencies of responses for men and women with 95\% confidence intervals were computed for all variables. Logistic regression was used to analyse associations between socioeconomic status, health behaviours, and attitudes. Odds of unhealthy behaviours and attitudes were calculated for social classes III and IV/V, with class I/II as the reference group. Models were adjusted for age and sex, and for age, sex, and self rated health.

\section{RESULTS}

The numbers of respondents in social classes I/II, III, and IV/V were $579(36.8 \%), 675(42.5 \%)$, and $319(20.3 \%)$, respectively. As expected, cigarette smoking, lack of exercise, and low fruit and vegetable intake were more prevalent in lower social class respondents (table 1). A gradient across social class groups was observed for all behaviours, and differences remained after adjustment for age, sex, and self rated health. Poorer self rated health was also more prevalent in less affluent classes.

The mean ratings on the internal and chance locus of control scales were 3.59 (3.56 to 3.62) and 2.75 (2.72 to 2.79). A rating of four or more was taken to indicate strong internal beliefs, and three or more to indicate strong chance beliefs. Socioeconomic status was not associated with internal locus of control, but strong beliefs in the importance of chance in health were inversely associated with social class (table 2 ). The relation was unchanged by adjustment for self rated health.

A wide range of responses to the future salience items were obtained. We categorised participants who responded rarely and not very often to all seven time frames as seldom thinking about the future. The likelihood of seldom thinking about the future was consistently inversely associated with socioeconomic status after adjusting for age, sex, and self rated health (table 2).

Some $10.2 \%$ of respondents believed they would not live beyond 70 years, $34.7 \%$ that they would live for $70-79$ years, $42.0 \%$ for $80-89$ years, and $13.1 \%$ for 90 or more years. We computed the proportion who believed that they would live for less than 80 years. Respondents currently aged over 75 years 
Table 2 Health locus of control, future salience, life expectancy, and health consciousness

\begin{tabular}{|c|c|c|c|c|}
\hline \multirow[b]{2}{*}{ Social class } & \multicolumn{2}{|c|}{ Percentage } & \multirow{2}{*}{$\begin{array}{l}\text { Odds ratio for social class, } \\
\text { adjusted for age and sex ( } 95 \% \\
\text { CI) }\end{array}$} & \multirow{2}{*}{$\begin{array}{l}\text { Odds ratio for social class, } \\
\text { adjusted for age, sex, and self } \\
\text { rated health }(95 \% \mathrm{Cl})\end{array}$} \\
\hline & Men & Women & & \\
\hline \multicolumn{5}{|c|}{ High internal locus of control } \\
\hline Class I/II & 36.4 & 40.7 & 1 & 1 \\
\hline Class III & 44.3 & 40.8 & 1.19 (0.94 to 1.49$)$ & $1.27(1.01$ to 1.61$)$ \\
\hline Class IV/V & 37.5 & 43.7 & $1.15(0.87$ to 1.53$)$ & $1.29(0.96$ to 1.72$)$ \\
\hline \multicolumn{5}{|c|}{ High chance locus of control } \\
\hline Class I/II & 26.3 & 32.3 & 1 & 1 \\
\hline Class III & 41.6 & 48.7 & 1.97 (1.56 to 2.50$)$ & 1.96 (1.55 to 2.49 ) \\
\hline Class IV/V & 47.3 & 58.0 & $2.70(2.02$ to 3.60$)$ & 2.68 (2.00 to 3.58$)$ \\
\hline \multicolumn{5}{|c|}{ Seldom thinking about the future } \\
\hline Class I/II & 31.3 & 36.1 & 1 & 1 \\
\hline Class III & 40.5 & 39.8 & $1.28(1.00$ to 1.63$)$ & 1.31 (1.03 to 1.67$)$ \\
\hline Class IV/V & 50.9 & 44.9 & $1.62(1.21$ to 2.18$)$ & 1.69 (1.25 to 2.28$)$ \\
\hline \multicolumn{5}{|c|}{ Expecting not to live beyond the age of 80} \\
\hline Class I/II & 49.6 & 38.8 & 1 & 1 \\
\hline Class III & 58.5 & 45.6 & $1.42(1.10$ to 1.83$)$ & $1.27(0.98$ to 1.65$)$ \\
\hline Class IV/V & 61.6 & 48.3 & $1.62(1.17$ to 2.24$)$ & $1.38(0.99$ to 1.93$)$ \\
\hline \multicolumn{5}{|c|}{ Seldom thinking about things to do to keep healthy } \\
\hline Class I/II & 22.8 & 19.1 & 1 & 1 \\
\hline Class III & 29.3 & 31.3 & 1.60 (1.23 to 2.08$)$ & 1.66 (1.27 to 2.17$)$ \\
\hline Class IV/V & 26.4 & 30.2 & $1.43(1.03$ to 1.97$)$ & 1.52 (1.09 to 2.11$)$ \\
\hline \multicolumn{5}{|c|}{ Frequently thinking about future illness } \\
\hline Class I/II & 22.4 & 24.9 & 1 & 1 \\
\hline Class III & 25.1 & 22.2 & $1.02(0.78$ to 1.33$)$ & $0.94(0.72$ to 1.23$)$ \\
\hline Class IV/V & 26.8 & 25.1 & $1.19(0.86$ to 1.64$)$ & $1.05(0.76$ to 1.46$)$ \\
\hline
\end{tabular}

Table 3 Attitudinal factors, self rated health, and health behaviours

\begin{tabular}{|c|c|c|c|c|}
\hline & $\begin{array}{l}\text { Cigarette smoking } \\
\text { odds ratio }(95 \% \mathrm{CI})\end{array}$ & $\begin{array}{l}\text { No vigorous physical } \\
\text { activity odds ratio } \\
(95 \% \mathrm{Cl})\end{array}$ & $\begin{array}{l}\text { Fruit: fewer than one } \\
\text { portion per day odds } \\
\text { ratio }(95 \% \mathrm{Cl})\end{array}$ & $\begin{array}{l}\text { Vegetables: fewer than } \\
\text { one portion per day } \\
\text { odds ratio }(95 \% \mathrm{CI})\end{array}$ \\
\hline Self rated health (fair/poor) & $1.34(1.18$ to 1.51$)$ & $1.69(1.50$ to 1.91$)$ & 1.22 (1.09 to 1.38$)$ & $1.46(1.29$ to 1.66$)$ \\
\hline High chance locus of control & $1.29(1.01$ to 1.65$)$ & $1.11(0.87$ to 1.41$)$ & $1.20(0.94$ to 1.53$)$ & $1.50(1.16$ to 1.93$)$ \\
\hline Seldom thinking about the future & $1.41(1.08$ to 1.84$)$ & $1.03(0.79$ to 1.33$)$ & $1.19(0.92$ to 1.54$)$ & $1.58(1.20$ to 2.08$)$ \\
\hline Not expecting to live $>80$ years & $1.53(1.19$ to 1.97$)$ & $1.19(0.93$ to 1.51$)$ & $1.29(1.01$ to 1.64$)$ & $1.25(0.97$ to 1.61$)$ \\
\hline Seldom thinking about things to do to stay healthy & 1.53 (1.15 to 2.05$)$ & $1.87(1.39$ to 2.51$)$ & $1.95(1.47$ to 2.58$)$ & 1.69 (1.26 to 2.27$)$ \\
\hline
\end{tabular}

were excluded from these analyses, as a number were already over 80 , and the proportion answering "don't know" to the item was greater than for younger participants. The proportion of men who believed that they would live for less than 80 years was $54.7 \%$ ( 50.8 to 58.7 ), which was larger than the proportion of women $(43.5 \%, 39.9$ to 47.2$)$. Expecting a life span of less than 80 years was associated with lower socioeconomic status (table 2); however, the gradient was attenuated after adjustment for self rated health, indicating that socioeconomic differences in expectations of life span are attributable in part to perceptions of health.

The proportion who stated that they thought about things they might do to keep healthy at least once a day was $42.7 \%$; a further $31 \%$ thought about things to keep healthy every two or three days or about once a week, while the remaining $26.3 \%$ thought about such things less than weekly. We compared the proportions of participants in different social classes who seldom thought about things they could do to keep healthy (defined here as less than weekly). The odds of seldom thinking about things that can be done to keep healthy were greater in classes III and IV/V than in classes I/II, after adjustment for age, sex, and self rated health.

Frequently thinking about things that can be done to keep healthy might have the unfortunate consequence of preoccupation with illness. We therefore carried out similar analyses of responses to the question concerning how often participants thought about future illness. However, responses were not related to socioeconomic status, so the gradient in think- ing about keeping healthy was not reflected in preoccupation with illness.

Multivariate models testing relations between attitudinal factors and the health behaviours are summarised in table 3. Poorer self rated health was associated with smoking, lack of physical activity, and not eating fruit and vegetables daily, so this factor was included in all the models. Seldom thinking about things to do to stay healthy was associated with all four unhealthy behavioural choices, independently of age, sex, and self rated health. Seldom thinking about the future and higher chance locus of control beliefs were both independently related to the likelihood of smoking and not eating vegetables. Expectations of a limited life span were independently associated with cigarette smoking and eating fruit less than daily.

\section{DISCUSSION}

Socioeconomic differences in health behaviours are associated with a number of factors such as childhood background and education, material hardship, and social integration. ${ }^{11}{ }^{12}$ Some of these factors are likely to exert their effects through more proximal determinants of behaviour such as attitudes, motivation, beliefs in health benefits, self efficacy, and perceived barriers to healthy choices, all of which are associated with individual differences in health behaviours. ${ }^{13}$ The distribution of these proximal cognitive and motivational determinants across the social gradient has not been studied extensively, although socioeconomic differences in motives underlying food choice have been described, ${ }^{6}$ along with 
socioeconomic differences in attitudes to screening participation, ${ }^{14}$ weight control, ${ }^{15}$ and preventive dental visits. ${ }^{16}$ This study focused on attitudes and expectations that might underlie a range of health behaviours, rather than those associated with specific behavioural choices.

The three factors that emerged most consistently as being associated both with socioeconomic status and with the likelihood of carrying out healthy behaviours were chance health locus of control, future salience, and conscious awareness of the influence of lifestyle on health. All three factors were related to social class after adjustment for age, sex, and self rated health. Health consciousness was independently associated with the four behaviours included in the study, while future salience and chance health locus of control were related to two of the four behaviours. Expectations of a shorter life span were also more frequent in lower social class respondents, although this effect was attenuated when self rated health was taken into account. Similar results relating subjective life expectancy with educational attainment were reported by Mirowsky and Ross in a US sample. ${ }^{17}$ As premature mortality is more common in lower social status groups, the limited expectations of life span might reflect accurate perceptions of current and future health. Shorter expected life expectancy was associated with smoking and unhealthy dietary choices, and this might reflect lack of motivation to change on the part of those who foresaw a shorter future, or a reduced life expectancy estimate because of awareness of the adverse effects of smoking and eating badly.

The social gradient in sense of control has previously been reported, with higher levels of fatalism and lower beliefs in personal control in lower socioeconomic status groups. ${ }^{18}$ But general sense of control does not necessarily translate into beliefs in control over specific spheres of life and activity. ${ }^{19}$ In this survey we found no differences between social classes in beliefs in internal locus of control, but only in chance locus of control. This supports the argument that control beliefs are multidimensional, ${ }^{10}$ and that individuals can simultaneously hold strong beliefs in the relevance of their own actions, and in the play of chance. Whether or not this pattern reflects greater fatalism in lower socioeconomic groups is disputed. Blaxter has argued that because people in lower social classes have greater personal experience of chronic disease and premature mortality than more affluent groups, they will also have greater experience both of survival despite the presence of risk factors, and of illness despite healthy lifestyles. ${ }^{20}$ Luck or chance may be invoked to interpret these risk factor effects, and may coexist with firm beliefs in personal control. None the less, the association of high chance health locus of control with smoking, sedentary lifestyles, and diets low in fruit and vegetables suggests that such beliefs may be antithetical to healthy lifestyles.

An association between socioeconomic status and future salience was also apparent. The social class gradient in seldom thinking about the future was striking, with nearly half of the respondents in semi-skilled and unskilled classes stating that they did not think about either the short-term or long term future very often. Ethnographers and social scientists in the post-war period described the short time perspectives of families in mining and dockland communities, which seemed logical consequences of hazardous working conditions, poverty, and marked limitations in life chances. ${ }^{21}{ }^{22}$ This study suggests that variations in future orientation are more pervasive, affecting not only severely deprived groups but people of intermediate social status. The moderate associations between future orientation, smoking and dietary choice have implications for health promotion. Efforts to encourage healthy lifestyles by invoking future health benefits may be less successful in sectors of society in which thinking about the future is limited.
This study was cross sectional, so causal conclusions cannot be drawn. The identification of differences in attitudes related to health between social classes is not intended to minimise the importance of material, developmental, and other determinants of variations in health behaviours across social groups. ${ }^{1123}$ Rather, the purpose of these analyses was to investigate attitudes that could mediate socioeconomic differences in healthy lifestyle, as these might be more amenable to change than other determinants. Longitudinal and intervention studies will be required to test these possibilities rigorously.

\section{Authors' affiliations}

J Wardle, Cancer Research UK, Health Behaviour Unit, Department of Epidemiology and Public Health, University College London, UK A Steptoe, Psychobiology Group, Department of Epidemiology and Public Health, University College London

Funding: this research was supported by Cancer Research UK.

Conflicts of interest: none.

\section{REFERENCES}

1 Pill R, Peters TJ, Robling MR. Social class and preventive health behaviour: a British example. J Epidemiol Community Health 1995:49:28-32.

2 Lowry R, Kann L, Collins JL, et al. The effect of socioeconomic status on chronic disease risk behaviors among US adolescents. JAMA 1996;276:792-7

3 Lantz PM, House JS, Lepkowski JM, et al. Socioeconomic factors, health behaviors, and mortality: results from a nationally representative prospective study of US adults. JAMA 1998;279:1703-8.

4 Jarvis MJ. Patterns and predictors of smoking cessation in the general population. Prog Respir Res 1997;28:151-64.

5 Martikainen PT, Marmot MG. Socioeconomic differences in weight gain and determinants and consequences of coronary risk factors. Am J Clin Nutr 1999:69:719-26.

6 Steptoe A, Wardle J. Motivational factors as mediators of socioeconomic variations in dietary intake patterns. Psychol Health 1999; 14:391-402.

7 Parmenter K, Waller J, Wardle J. Demographic variation in nutrition knowledge in England. Health Educ Res 2000;15:163-74.

8 Steptoe A, Wardle J. Locus of control and health behaviour revisited: a multivariate analysis of young adults from 18 countries. BrJ Psychol 2001;92:659-72.

9 Office of National Statistics Technical Report. Omnibus survey. London: The Stationery Office, 1999.

10 Wallston KA, Wallston BS, DeVellis RF. Development of the multidimensional health locus of control (MHLC) scale. Health Educ Mono 1978;6:160-70.

11 Lynch JW, Kaplan GA, Salonen JT. Why do poor people behave poorly? Variation in adult health behaviours and psychosocial characteristics by stages of the socioeconomic lifecourse. Soc Sci Med 1997;44:809-19.

12 Stronks K, van de Mheen HD, Looman CW, et al. Cultural, material, and psychosocial correlates of the socioeconomic gradient in smoking behavior among adults. Prev Med 1997;26:754-66.

13 Fishbein $\mathbf{M}$, Triandis $\mathrm{HC}$, Kanfer FH, et al. Factors influencing behavior and behavior change. In: Baum A, Revenson TA, Singer JE, eds. Handbook of health psychology. Mahwah, NJ: Lawrence Erlbaum, 2001:3-17.

14 Wardle J, Sutton S, Williamson S, et al. Psychosocial influences on older adults' interest in participating in bowel cancer screening. Prev Med 2000;31:323-34

15 Wardle J, Griffith J. Socioeconomic status and weight control practices in British adults. J Epidemiol Community Health 2001;55:185-90.

16 Chen MS, Land KC. Socioeconomic status (SES) and the Health Belief Model: LISREL analysis of unidimensional versus multidimensional formulations. J Soc Behav Pers 1990;5:263-84.

17 Mirowsky J, Ross CE. Socioeconomic status and subjective life expectancy. Soc Psychol Q 2000;63:133-51

18 Lachman ME, Weaver SL. The sense of control as a moderator of social class differences in health and well-being. J Pers Soc Psychol 1998;74:763-73.

19 Rotter J. Some problems and misconceptions related to the construct of internal versus external control of reinforcement. J Consult Clin Psychol 1975;43:56-67.

20 Blaxter M. Whose fault is it? People's own conceptions of the reasons for health inequalities. Soc Sci Med 1997;44:747-56.

21 Zweig F. Men in the pits. London: Gollancz, 1948.

22 Klein J. Samples from English cultures. London: Routledge and Kegan Paul, 1965

23 Macintyre S. The Black Report and beyond: what are the issues? Soc Sci Med 1997;44:723-45 